\section{YOUNG PATIENTS WITH HEART FAILURE OFTEN DO NOT HAVE MAJOR ECG ABNORMALITIES}

doi:10.1136/heartjnl-2012-301877b.16

${ }^{1} \mathrm{~A}$ Mahmood, ${ }^{*} \mathrm{M}$ C Petrie, ${ }^{2} \mathrm{C}$ Wong, ${ }^{2} \mathrm{~A}$ P Davie. ${ }^{1}$ University of Glasgow, Glasgow, UK; ${ }^{2}$ Golden Jubilee National Hospital, Glasgow, UK

Background It is commonly held that a normal ECG rules out the diagnosis of heart failure ${ }^{1}$; however this has only been demonstrated in the elderly. ${ }^{2}$ Do young people with heart failure always have major ECG abnormalities?

Aim To determine the proportion of patients aged below 65 who had heart failure with LVSD who present with ECGs without major abnormalities.

Methods 100 consecutive admissions to the Scottish National Advanced Heart Failure Service at the Golden Jubilee National Hospital, Glasgow who were aged below 65 and had an echocardiogram and ECG available. Ejection fraction was quantified using the Simpson's biplane method. ECGs were independently assessed by two cardiologists blinded to the result of the echocardiograms. Any disagreements were resolved by a third cardiologist. Majorly abnormal ECGs contained $\geq 1$ of: $\mathrm{Q}$-waves, left ventricular hypertrophy (LVH), bundle branch block and atrial fibrillation. Presence of $\mathrm{Q}$ waves was assessed subjectively by the two assessors and then using criteria as defined by the Universal Definition of Myocardial Infarction by a third assessor. Similarly the presence of LVH was assessed subjectively and using the SokolowLyon Index. Minor abnormalities of ECG included atrial enlargement, bradycardia, tachycardia, broadening of ORS complex, poor $\mathrm{R}$ wave progression, left or right axis deviation, myocardial ischaemia, first degree atrioventricular block, and non-specific ST-T wave changes.

Results Of 100 consecutive patients, 77 were males and 23 females. Mean age was 50 years (range 18-64). 76 had major ECG abnormalities. 22 had only minor ECG abnormalities and no major ECG abnormalities; two had no abnormalities. All patient groups had marked LV systolic dysfunction (ejection fractions of $28.6 \% \pm 2.8$, $28.4 \% \pm 3.4,25.5 \% \pm 6.9$ for those with major, minor and no abnormalities on ECG respectively). Analysis by criteria for $\mathrm{Q}$ waves demonstrated 71 had major ECG abnormalities, 27 had minor ECG abnormalities and 2 had none. Analysis by criteria for LVH gave the same results as the initial cardiological analysis.

Conclusion Only $71 \%-76 \%$ of patients under the age of 65 have major ECG abnormalities, compared to $98 \%$ of patients of any age (2). Young patients with heart failure often have minor ECG abnormalities in the absence of major ECG abnormalities. The index of suspicion of heart failure in young symptomatic patients should be high even in the absence of major ECG.

\section{REFERENCES}

1. Khan NK, Goode KM, Cleland JG, et al. Prevalence of ECG abnormalities in an international survey of patients with suspected or confirmed heart failure at death or discharge. Eur J Heart Fail 2007;9:491-501.

2. Davie AP, Francis CM, Love MP, et al. Value of the electrocardiogram in identifying heart failure due to left ventricular systolic dysfunction. BMJ 1996:312:222.

\section{MICROVOLT T-WAVE ALTERNANS (MTWA) TESTING IN "REAL WORLD" HEART FAILURE (HF): A STUDY OF PREVALENCE AND INCREMENTAL PROGNOSTIC VALUE}

doi:10.1136/heartjnl-2012-301877b.17

${ }^{1} \mathrm{C}$ E Jackson, * ${ }^{1} \mathrm{R}$ C Myles, II K Tsorlalis, ${ }^{1} \mathrm{~J}$ R Dalzell, ${ }^{1} \mathrm{~J}$ P Rocchiccioli, ${ }^{2} \mathrm{R}$ J Spooner, ${ }^{3} \mathrm{~J} \mathrm{R}$ Rodgers, ${ }^{4} \mathrm{~V}$ Bezlyak, ${ }^{4} \mathrm{~N}$ Greenlaw, ${ }^{4}$ I Ford, ${ }^{5} \mathrm{M} \mathrm{C}$ Petrie, ${ }^{1} \mathrm{~S} \mathrm{M}$ Cobbe, ${ }^{1} \mathrm{~J} J$ V McMurray. ${ }^{1}$ BHF Glasgow Cardiovascular Research Centre, University of Glasgow, Glasgow, UK; ${ }^{2}$ Department of Biochemistry, Gartnavel General Hospital,
Glasgow, UK; ${ }^{3}$ Glasgow Royal Infirmary, Glasgow, UK; ${ }^{4}$ Robertson Centre for Biostatistics, University of Glasgow, Glasgow, UK; ${ }^{5}$ Scottish National Advanced Heart Failure Service, Golden Jubilee National Hospital, Glasgow, UK

Background Ventricular arrhythmias contribute to the high risk of death in heart failure (HF) and can be treated with an implantable cardioverter-defibrillator (ICD). Microvolt T-wave alternans (MTWA) testing examines beat-to-beat fluctuations in the morphology of the T-wave. Alternans is believed to reflect dynamic instability of repolarisation and to be linked, mechanistically, to ventricular arrhythmias. Observational studies in highly selected populations have suggested that MTWA testing may identify individuals likely to benefit from a primary prevention ICD. The aims of this study were to evaluate the applicability of MTWA testing in an unselected cohort of patients recently hospitalised with HF and determine the prevalence and incremental prognostic value of an abnormal test.

Methods Consecutive admissions with confirmed HF (typical clinical findings and $\mathrm{BNP}>100 \mathrm{pg} / \mathrm{ml}$ ) were recruited in three hospitals from 1 December 2006 to 12 January 2009. Survivors were invited to attend 1-month post-discharge for MTWA testing (HearTWave II, Cambridge Heart)

Results 648 of 1003 patients recruited returned for MTWA testing (58\% males, mean age 70.8 years). 318 patients (49\%) were ineligible for MTWA testing due to atrial fibrillation (AF), pacemakerdependency or inability to exercise. Of the 330 patients who underwent MTWA treadmill testing, 100 (30\%) were positive, 78 (24\%) were negative and 152 (46\%) were indeterminate. Failure to achieve the target heart rate due to chronotropic incompetence, secondary to $\beta$-blocker therapy or physical limitations, accounted for $75 \%$ of indeterminate tests. 131 deaths occurred during a mean follow-up of 18 months. $23 \%$ of ineligible patients died vs $17 \%$ of eligible patients. $12 \%, 20 \%$ and $19 \%$ of patients with a positive, negative and indeterminate test, respectively, died $(p=0.24)$. MTWA results were analysed in the accepted way of non-negative (positive and indeterminate) and negative, but there was still no difference in mortality between the groups $(p=0.39)$. MTWA showed no incremental prognostic value in a multivariable mortality model. The independent predictors of mortality were: lower body mass index (HR 0.96 [95\% CI 0.93 to 0.99], p=0.01), New York Heart Association class III-IV (1.72 [95\% CI 1.2 to 2.47], $\mathrm{p}=0.003$ ), previous myocardial infarction (1.68 [95\% CI 1.18 to 2.4$], p=0.004$ ), elevated B-type natriuretic peptide concentration (1.36 [95\% CI 1.12 to 1.65], $\mathrm{p}=0.002)$ and elevated troponin (1.57 [95\% CI 1.04 to 2.37], $\mathrm{p}=0.03$ )

Conclusion MTWA treadmill-testing was not widely applicable in typical patients with HF and failed to predict mortality risk. At present MTWA cannot be endorsed as a tool for improving risk stratification in HF.

\section{THE BREAST CANCER, EARLY DISEASE: TOXICITY FROM THERAPY WITH EPIRUBICIN REGIMENS "C CARDIAC ASSESSMENT AND RISK EVALUATION (BETTER-CARE), CARDIOVASCULAR MAGNETIC RESONANCE (CMR) SUB- STUDY: CYCLE 1 CHANGES PREDICT LATE ANTHRACYCLINE CARDIOTOXICITY}

doi:10.1136/heartjnl-2012-301877b.18

${ }^{1} \mathrm{G}$ C Smith, ${ }^{*} \mathrm{P}$ Kotwinski, ${ }^{2} \mathrm{~J}$ Sanders, ${ }^{2} \mathrm{~J}$ Cooper, ${ }^{2} \mathrm{~L} \mathrm{Ma},{ }^{3} \mathrm{~A}$ Jones, ${ }^{4} \mathrm{M} \mathrm{G}$ Mythen, ${ }^{2} \mathrm{H}$ E Montgomery, ${ }^{1} \mathrm{D} \mathrm{J}$ Pennell. ${ }^{1}$ Royal Brompton Hospital, London, UK; ${ }^{2}$ University College London, London, UK; ${ }^{3}$ Royal Free Hospital, London, UK; ${ }^{4}$ University College London and University College London Hospitals, London, UK

Introduction A growing number of patients are at risk from chronic anthracycline cardiotoxicity (cAC) as a result of improving prognosis of cancer. This is true even at low, adjuvant doses. In breast 